\title{
27 DECIDING FOR OTHERS: A CLINICIAN'S VIEW
}

P Saul' ${ }^{1} J o h n$ Hunter Hospital, Newcastle, NSW, Australia

10.1136/bmjspcare-2013-000491.27

Background The majority of people in Australia die in acute care. Up to $95 \%$ of them will lack capacity to make treatment decisions at the end of life, and these decisions will be made by uninformed family members and caring strangers.

Methods But what do we know about deciding for others? Two sources of knowledge come to mindempirical evidence from surveys and other scientific investigations, and philosophical explorations of advance statements, substituted judgments and best interests. The empirical evidence suggests that people differ considerably in the extent to which they wish to decide for others, that they are skeptical about the medical information they are given, that they have a low awareness of the likely preferences of the person they are deciding for, and that they do not accept the hierarchies of the various legal provisions. In legal terms, then, deciding for others rests on somewhat uncertain ground, especially when the decision to be made is about the end of life.

Discussion Legislation about deciding for others at EOL has a number of functions-principally (and wholly in the case of NSW) to protect the vulnerable. Other functions: providing standardised forms as evidence of prior wishes, indemnifying doctors who follow these wishes, and providing some guidance about best interests decisions, are variably included in different jurisdictions.

Conclusion But what do clinicians want? I would suggest: recognition of the need to make EOL decisions on behalf of others, of the need to protect vulnerable people from reckless overtreatment as well as undertreatment, clarification of the role of the family, regular review, transparency of decisions in tribunals, a process for establishing the validity of directives, and harmony with adjacent jurisdictions. This paper reviews current efforts from the UK and Australia, and suggests some lobbying may be required. 